PONTIFÍCIA UNIVERSIDADE CATÓLICA DO RIO DE JANEIRO

Avaliação de Empresas com Mensuração de Risco Através da Simulação de Monte Carlo

Guilherme de Jesus do Nascimento Filho

Trabalho de Conclusão de Curso

Centro de CIÊNCIAS SOCIAIS - CCS

DEPARTAMENTO de AdMINISTRAÇÃo

Graduação em Administração de Empresas 
Guilherme de Jesus do Nascimento Filho

\section{Avaliação de Empresas com Mensuração de Risco Através da Simulação de Monte Carlo}

Trabalho de Conclusão de Curso

Trabalho de Conclusão de Curso, apresentado ao programa de graduação em Administração da PUC-Rio como requisito parcial para a obtenção do título de graduação em Administração.

Orientador: Fernando Carlos Rodrigues Cortezi

Rio de Janeiro

Novembro de 2018. 


\section{Resumo}

Nascimento, Guilherme. Cortezi, Fernando. Mesuraçao do Risco em Avaliação de empresas. Rio de Janeiro, 2018. 31 p. Trabalho de Conclusão de Curso - Departamento de Administração. Pontifícia Universidade Católica do Rio de Janeiro.

O objetivo deste trabalho é realizar a avaliação de uma empresa utilizando o método de fluxo de caixa descontado, a fim de definir o valor de mercado da companhia e o valor justo de suas ações. Como o referido modelo não captura as incertezas das premissas utilizadas em sua construção, foi proposta a utilização da simulação de Monte Carlo como uma ferramenta auxiliar para análise das possíveis variações no valor da empresa e, por consequência, no preço das ações. Como resultado da aplicação desta ferramenta, foram estimadas probabilidades para o valor de mercado de uma empresa do setor de telecomunicações e o seu respectivo preço por ação.

Palavras- chave

Valuation, Avaliação de empresas, Simulação de Monte Carlo, Tim 


\section{Sumário}

1. Introdução 1

1.1. Objetivo do estudo 2

1.2. Delimitações do estudo 2

2. Referencial Teórico 3

2.1. Avaliação por fluxo de caixa descontado 3

2.1.1. Fluxo de caixa livre do acionista 3

2.1.2. Fluxo de caixa livre do projeto 5

2.2. O passo a passo do Valuation 5

2.2.1. Projeção dos fluxos de caixa livre do projeto 6

2.2.2. Cálculo da taxa de desconto (WACC) 7

2.2.2.1. Custo da dívida com credores 8

2.2.2.2. Custo do capital próprio 8

2.2.3. Valor presente dos fluxos de caixa 11

2.3. Simulação de Monte Carlo 12

$\begin{array}{ll}\text { 2.4. Outros modelos da avaliação } & 14\end{array}$

3. Metodologia 15

3.1. Coleta de dados 15

3.2. Projeção dos fluxos de caixa 15

3.3. Cálculo do WACC 15

3.4. Desconto dos fluxos de caixa 16

3.5. Aplicação da simulação de Monte Carlo 16

4. Apresentação e análise dos resultados 17

$\begin{array}{ll}\text { 4.1. Sobre a Tim } & 17\end{array}$

4.1.1. Composição acionária 18

4.2. Avaliação da companhia 18

4.2.1. Principais premissas 18

4.2.1.1. Premissas para a projeção dos fluxos de caixa 18

$\begin{array}{ll}\text { 4.2.1.2. Premissas para o cálculo do WACC } & 21\end{array}$ 
4.2.1.3. Premissas para o cálculo da taxa de crescimento $(\mathrm{g}) \quad 23$

4.2.2. Projeção do fluxo de caixa livre do projeto 24

4.2.3. Cálculo do WACC 24

4.2.4. Resultado da avaliação 25

4.3. Simulação de Monte Carlo 26

5. Conclusões 29

$\begin{array}{ll}\text { Referências Bibliográficas } & 30\end{array}$ 


\section{Introdução}

A avaliação de uma empresa ou de ativos financeiros está diretamente relacionada com a capacidade da mesma gerar fluxos de caixa dentro de sua atividade econômica (TITMAN; MARTIN, 2010). Sendo assim, a avaliação financeira por si só deve refletir os resultados financeiros e operacionais do ativo avaliado.

No mercado financeiro, o processo para estimar o valor de uma empresa é denominado de "Valuation". Esse processo é utilizado por profissionais do mercado para avaliar diversos tipos de ativos, desde empresas e projetos até imóveis e ações. Sendo assim, podemos afirmar de acordo com Damodaran (1997), que o valuation desempenha um papel fundamental no que diz respeito a tomada de decisão e gestão de ativos.

Existem inúmeros métodos de avaliação de ativos com diferentes níveis de complexidade, os principais segundo Damodaran (1997) são: Avaliação por Fluxo de Caixa Descontado (FCD), Avaliação relativa (múltiplos de mercado) e a Avaliação de direitos contingentes. Marques et al. (2010) afirmam que a avaliação por fluxo de caixa descontado representa o preço do ativo relacionado ao fluxo de caixa gerado no futuro, descontado por uma taxa de risco apropriada. A metodologia de avaliação relativa utiliza uma variável comum entre ativos comparáveis, como por exemplo, lucros, fluxos de caixa, valor contábil, vendas, entre outros. Já o método de avaliação de direitos contingentes mede o valor de ativos que possuem características de opções. Cada método utiliza informações e premissas distintas para determinar o valor de um mesmo ativo e, por este motivo, pode haver grandes diferenças entre os resultados obtidos em cada um (DAMODARAN, 1997; TITMAN; MARTIN, 2010).

Conforme defendem Titman e Martin (2010), todo método de avaliação, mesmo que reconhecidamente eficiente e sofisticado, envolve um determinado nível de incerteza. Isto ocorre em função da grande dificuldade em prever os resultados futuros da companhia e até mesmo do ambiente econômico em que a mesma está inserida. Com o intuito de minimizar as incertezas e o risco de erro inerentes de uma avaliação, este estudo propõe a utilização da simulação de Monte Carlo como uma ferramenta auxiliar de análise das possíveis variações do 
valor implícito de um ativo, afim de possibilitar um melhor resultado do modelo de avaliação.

\subsection{Objetivo do estudo}

Este estudo tem por objetivo a aplicação prática do modelo de avaliação por fluxo de caixa descontado e a realização da simulação de Monte Carlo, a fim de calcular o valor de mercado da empresa TIM PARTICIPAÇÕES S.A. e o valor justo por ação da companhia, considerando as incertezas oriundas das projeções financeiras necessárias no processo de valuation.

Além disso, são objetivos complementares ao estudo:

- Calcular o custo de capital da Tim;

- Apresentar de forma detalhada o método de avaliação por fluxo de caixa descontado;

- Identificar quais variáveis têm maior influência no valor da companhia, através da simulação de Monte Carlo;

- Realizar a projeção dos fluxos de caixa para os próximos 5 anos (2018 a 2022).

\subsection{Delimitações do estudo}

Neste estudo, foram utilizadas apenas as informações divulgadas pela própria empresa em seu site, além das demonstrações financeiras anuais auditadas e divulgadas obrigatoriamente.

Para calcular o custo de capital da empresa, foi utilizado o Beta do setor de telecomunicações, obtido no site do Damodaran e alavancado de acordo com a estrutura de capital da empresa em análise.

Para a projeção dos fluxos de caixa, foi utilizado apenas o método de análise histórica da companhia, sem considerar informações de analistas, revistas e especialistas do mercado. 


\section{Referencial Teórico}

\subsection{Avaliação por fluxo de caixa descontado}

Este método consiste na ideia de que projetos e empresas possuem fluxos de caixa diferentes ao longo de sua vida útil e só podem ser avaliados de fato após ajustar corretamente o valor do dinheiro no tempo (TITMAN; MARTIN, 2010), ou seja, a avaliação por fluxo de caixa descontado é resumidamente trazer a valor presente os fluxos de caixa projetados de um ativo, através de um custo de capital estimado, chegando assim ao seu valor presente líquido (VPL).

Há basicamente duas formas possíveis de avaliação por fluxo de caixa descontado: a primeira consiste em avaliar o caixa gerado para os acionistas do negócio (fluxo de caixa livre do acionista - FCLA), já a segunda, tem por objetivo avaliar o ativo como um todo, incluindo a participação dos acionistas e outros detentores de direitos do negócio (fluxo de caixa livre do projeto - FCLP) (TITMAN; MARTIN, 2010).

\subsubsection{Fluxo de caixa livre do acionista}

O fluxo de caixa livre do acionista é o valor excedente de caixa da empresa, após suprir toda necessidade operacional e obrigações financeiras. Ou seja, é o caixa gerado após o pagamento dos custos e despesas operacionais, incluindo pessoal, além de juros e principal, e novos investimentos em ativos fixos e capital de giro (DAMODARAN, 1997).

De acordo com Titman e Martin (2010), o fluxo de caixa do acionista pode ser calculado a partir de duas perspectivas, a primeira, consiste em um projeto financiado exclusivamente com capital próprio (não alavancado), dessa forma, não há despesas com juros ou pagamento de principal. Em contrapartida, toda necessidade de capital é financiada com patrimônio líquido.

O fluxo de caixa livre do acionista de um projeto financiado exclusivamente por capital próprio, pode ser calculado conforme mostra a figura a seguir. 
Figura 1: Cálculo do Fluxo de Caixa Livre do Acionista

Para um Projeto Não Alavancado

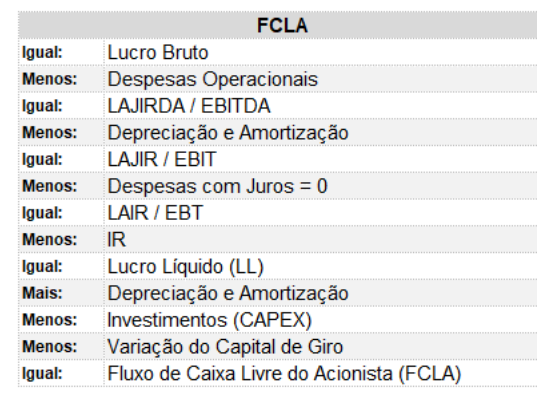

Fonte: Adaptado de Titman; Martin (2010, p. 65)

A segunda perspectiva, constitui-se ao calcular o fluxo de caixa do acionista para um projeto alavancado, ou seja, um projeto que utiliza capital de terceiros para financiar parte de seus ativos. Ao calcular o fluxo de caixa do acionista para um projeto que utiliza capital de terceiros, notam-se algumas diferenças em relação ao fluxo de caixa de um projeto não alavancado. Primeiro, há uma entrada de caixa proveniente de novos financiamentos (aporte financeiro). Segundo, se torna necessário realizar o pagamento de juros e principal durante o período do empréstimo (TITMAN; MARTIN, 2010).

Outro ponto importante ao calcular o fluxo de caixa de um projeto alavancado, de acordo com Damodaran (1997), é o benefício fiscal originado pelo pagamento de juros. As despesas financeiras, neste caso o pagamento de juros proveniente da dívida com terceiros, são dedutíveis do imposto de renda, ou seja, quando há um desembolso com despesa financeira, diminui-se o montante de imposto de renda a ser pago.

O fluxo de caixa livre do acionista de um projeto alavancado, pode ser calculado conforme mostra a figura a seguir.

Figura 2: Cálculo do Fluxo de Caixa Livre do Acionista

Para um Projeto Alavancado

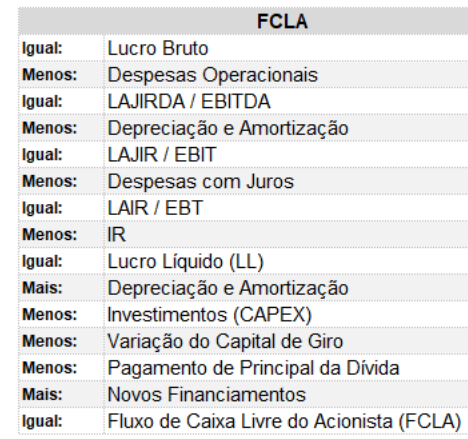

Fonte: Adaptado de Titman; Martin (2010, p. 69) 


\subsubsection{Fluxo de caixa livre do projeto}

Diferente do fluxo de caixa para o acionista, essa abordagem estima a geração de recursos provenientes das atividades operacionais da companhia, independente da origem do financiamento. Dessa forma, calcula-se o fluxo de caixa disponível para todos os credores (TITMAN; MARTIN, 2010).

O fluxo de caixa livre do projeto é calculado após o pagamento de todos os gastos operacionais e impostos, porém, antes de qualquer pagamento aos credores. De modo geral, o fluxo de caixa livre do projeto será sempre igual ao fluxo de caixa do acionista para um projeto não alavancado. Isso porque, em ambos não há o desembolso com despesas financeiras.

Assim, pode-se calcular o fluxo de caixa livre do projeto da seguinte maneira.

Figura 3: Cálculo do Fluxo de Caixa Livre do Projeto

\begin{tabular}{ll|}
\hline \multicolumn{1}{c|}{$\quad$ FCLP } \\
\hline Igual: & Lucro Bruto \\
Menos: & Despesas Operacionais \\
\hline Igual: & LAJIRDA / EBITDA \\
Menos: & Depreciação e Amortização \\
\hline Igual: & LAJIR / EBIT \\
Menos: & IR \\
\hline lgual: & Lucro Operacional liquido depois do IR (NOPAT) \\
Mais: & Depreciação e Amortização \\
Menos: & Investimentos (CAPEX) \\
Menos: & Variação do Capital de Giro \\
Igual: & Fluxo de Caixa Livre do Projeto (FCLP) \\
\hline
\end{tabular}

Fonte: Adaptado de Titman; Martin (2010, p. 73)

\subsection{O passo a passo do Valuation}

O processo de valuation consiste de três passos, conforme ilustrado na figura 4 a seguir. $O$ primeiro passo é prever os fluxos de entrada e saída de recursos esperados para o projeto ou empresa e o cronograma dos mesmos. Este primeiro passo é de fato o de maior complexidade e o que exige maior atenção em todo o processo, devido a impossibilidade de se prever o futuro com segurança, além de muitas vezes, não possuir informações de muita qualidade. Em seguida deve-se estipular uma taxa de risco adequada ao negócio. Esta taxa pode ser calculada, segundo Damodaran (1997), utilizando o modelo de custo médio ponderado do capital (WACC), que será explicado mais adiante com maior detalhe. Por fim, se torna necessário descontar os fluxos de caixa projetados pela taxa de risco calculada anteriormente (TITMAN; MARTIN, 2010, p. 53). 
Figura 4: Passos de uma avaliação por fluxo de caixa descontado

\begin{tabular}{l|l}
\hline Passos & Avaliação do investimento \\
\hline $\begin{array}{l}\text { Passo 1: Projetar o valor e o cronograma dos fluxos de } \\
\text { caixa futuros. }\end{array}$ & Projete os fluxos de caixa livre do projeto (FCLP). \\
"Quanto se espera que o projeto gere em termos de \\
caixa e quando?"
\end{tabular}

Fonte: Adaptado de Titman; Martin (2010, p. 53)

\subsubsection{Projeção dos fluxos de caixa livre do projeto}

O primeiro passo do processo de avaliação por fluxo de caixa descontado não pode ser realizado guiando-se por intuições pessoais. De acordo com o entendimento de Titman e Martin (2010), muitos gerentes e analistas são motivados a projetar fluxos de caixa desejados (otimistas) em vez de esperados (realistas), isto porque, muitas vezes a aprovação do projeto pode estar vinculada a bônus e outros tipos de ganhos pessoais. Com isto, pode-se entender que a projeção de fluxos de caixa otimistas pode ignorar pequenas falhas, que podem vir a aparecer na implementação do projeto (TITMAN; MARTIN, 2010).

Para não cometer este erro e realizar uma avaliação confiável de um ativo, é fundamental que se faça uma análise histórica de seu desempenho (se o mesmo possuir um histórico) (COPELAND et al., 2002). Feito isto, é possível estimar uma taxa de crescimento dos lucros e despesas para os próximos anos. Além da análise histórica, tais estimativas podem ser alcançadas de outras maneiras, como por exemplo, através da opinião de analistas especializados no mercado em questão, ou até mesmo por meio das expectativas da própria empresa (DAMODARAN, 1997).

O passo seguinte, é projetar os fluxos de caixa da empresa para os próximos anos, ou seja, é preciso definir as receitas e custos provenientes da operação da empresa, tomando como base uma taxa de crescimento predefinida. A partir disso, calcula-se a receita bruta, impostos, custos e despesas operacionais, além do EBITDA e depreciação. O ponto inicial para a construção do fluxo de caixa livre do projeto é o lucro operacional após o desconto de imposto de renda, denominado de NOPAT (Net Operating Profit After Tax). Em seguida, é preciso 
transformar o NOPAT em um fluxo de caixa livre do projeto (TITMAN; MARTIN, 2010), conforme os passos a seguir:

1ํ- Somar a depreciação e amortização de ativos, visto que, ambos não representam saída de caixa da empresa;

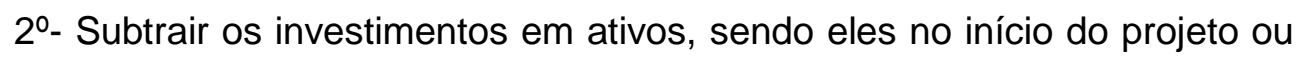
no decorrer dele;

3-ㅗ Por fim, subtrair os investimentos em capital de giro, necessários para financiar as operações.

Após realizar todos os passos chega-se ao fluxo de caixa livre do projeto. Este mesmo processo deve ser repetido para todos os anos projetados.

\subsubsection{Cálculo da taxa de desconto (WACC)}

De acordo com Damodaran (1997), o custo médio ponderado de capital (WACC) é a média ponderada dos meios de financiamento utilizados em um projeto ou empresa para financiar suas necessidades financeiras, podendo ser empréstimos em bancos, aporte de capital com acionistas, ou até mesmo financiamento com capital próprio. O WACC indica a taxa de retorno esperada pelas fontes de financiamento e, além disso, pode ser visto também como o custo de oportunidade dos investidores e a taxa de desconto usada para trazer os fluxos de caixa a valor presente (TITMAN; MARTIN, 2010).

Calcula-se o custo médio ponderado de capital através da seguinte fórmula, demonstrada na figura 5 :

Figura 5: Fórmula do custo médio ponderado de capital

$$
\text { WACC }=\mathrm{K}_{d}(1-\mathrm{T}) \mathrm{W}_{d}+\mathrm{k}_{e} \mathrm{~W}_{\mathrm{e}}
$$

Fonte: Adaptado de Titman; Martin (2010, p. 151)

\footnotetext{
WACC $=$ Custo médio ponderado de capital

$\mathrm{k}_{d}=$ Custo da dívida com credores

$\mathrm{w}_{d}=$ Peso associado a dívida com credores

$\mathrm{k}_{\theta}=$ Custo do capital próprio

$\mathrm{W}_{e}=$ Peso associado ao capital próprio

$\mathrm{T}=$ Alíquota de imposto de renda
} 


\subsubsection{Custo da dívida com credores}

O custo da dívida com credores pode ser calculado a partir das taxas aplicadas por instituições financeiras para conceder empréstimos e financiamentos. Essa taxa deve ser utilizada descontando-se a alíquota dos tributos sobre o lucro (IR), visto que, é gerado um benefício fiscal a partir do momento em que a empresa adquire uma dívida (MARTELANC; PASIN; PEREIRA, 2010).

Segundo Damodaran (1997), o custo do capital de terceiros pode ser afetado por três variáveis:

1a- O nível corrente das taxas de juros: O custo da dívida varia conforme a movimentação das taxas de juros do mercado. No Brasil a taxa básica de juros é a Selic.

2- O risco de inadimplência da empresa: Quanto maior o nível de inadimplência da empresa no mercado, maior será seu custo para tomar empréstimos.

3a- Os benefícios fiscais associados aos empréstimos: Isto é, a empresa adquire um benefício fiscal por pegar dinheiro emprestado, já que, os juros da dívida são dedutíveis do imposto de renda.

Com isso, calculamos o custo da dívida da seguinte forma.

Figura 6: Cálculo da dívida com credores

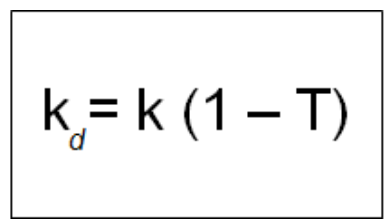

Fonte: Adaptado de Damodaran (1997, p.78)

$\mathrm{k}_{d}=$ Custo da dívida com credores líquida de IR

$\mathrm{k}=$ Custo da dívida com credores

$\mathrm{T}=$ Alíquota de imposto de renda

\subsubsection{Custo do capital próprio}

O custo do capital próprio, também conhecido como custo do patrimônio líquido, pode ser entendido como o retorno esperado pelos proprietários sobre o capital investido, segundo Damodaran (1997). O modelo utilizado neste estudo para estimar o custo do capital próprio, será o CAPM - Capital Asset Pricing Model. 
Seguindo o que dizem Copeland, Koller e Murrin (2002), Damodaran (1997) e Martelanc, Pasin e Pereira (2010), o CAPM é composto pelo retorno sobre os títulos ou carteiras livres de risco, como por exemplo, os títulos de longo prazo do tesouro norte-americano de 10 anos, mais o risco não diversificável da empresa, chamado de "Beta", multiplicado pelo prêmio de risco do mercado e por fim somado ao risco do país (uma taxa estimada para adequar o risco do mercado brasileiro).

Então, pode-se obter o custo do capital próprio a partir da seguinte fórmula:

Figura 7: Fórmula do CAPM

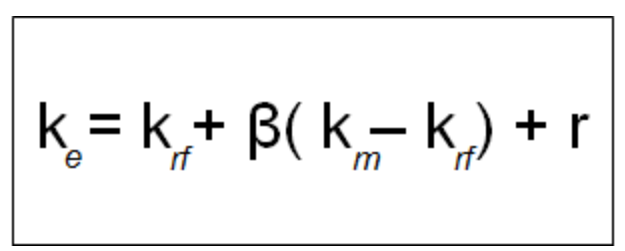

Fonte: Adaptado de Titman; Martin (2010, p. 165)

$\mathrm{k}_{e}=$ Custo do capital próprio

$\mathrm{k}_{\text {ff }}=$ Taxa livre de risco

$\beta=$ Coeficiente de risco do mercado

$\mathrm{k}_{m}=$ Retorno do mercado

$r=$ Risco país

\subsubsection{Taxa livre de risco}

A taxa livre de risco pode ser vista como o retorno sobre um título livre de risco de inadimplência (COPELAND et al., 2002). De acordo com Leal (2002), é utilizado como padrão pelo mercado, os retornos dos títulos do tesouro dos Estados Unidos para estimar a taxa livre de risco. Além disso, Titman e Martin (2010) sugerem também a utilização de títulos com vencimento de 10 a 20 anos.

\subsection{Beta}

O beta de uma empresa pode ser entendido como o risco sistemático (ou não diversificável) da mesma em relação ao retorno da carteira de mercado (TITMAN; MARTIN, 2010). Segundo o entendimento de Copeland et al. (2002), a melhor abordagem para se chegar ao beta de uma empresa listada na bolsa é a utilização das estimativas publicadas de beta do setor. Por este motivo, este estudo utilizou a estimativa de beta do setor de telecomunicações encontrado no site www.damodaran.com. Em seguida, deve-se desalavancar o beta do setor e realavanca-lo conforme a estrutura de capital da empresa avaliada. 
Para calcular o beta desalavancado utiliza-se a seguinte fórmula:

Figura 8: beta desalavancado

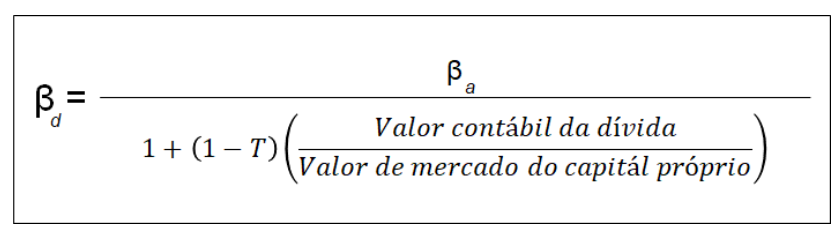

Fonte: Adaptado de Titman; Martin (2010, p. 169)

Para realavancar o beta, é utilizada a fórmula a seguir:

Figura 9: beta alavancado

$$
\beta_{a}=\beta_{d}\left(1+\left[(1-T)\left(\frac{\text { Valor contábil da dívida }}{\text { Valor de mercado do capitál próprio }}\right)\right]\right.
$$

Fonte: Adaptado de Titman; Martin (2010, p. 169)

Onde:

$$
\begin{aligned}
& \beta_{d}=\text { beta desalavancado } \\
& \beta_{a}=\text { beta alavancado } \\
& T=\text { alíquota de imposto de renda }
\end{aligned}
$$

Como afirma Damodaran (1997), o valor contábil da dívida (ou o custo da dívida) é o custo dos empréstimos obtidos pela empresa para financiar seus ativos. Dessa forma, pode ser obtido observando os empréstimos e financiamentos vindos do balanço patrimonial da companhia. Já o valor de mercado do capital próprio, pode ser calculado, segundo Titman e Martin (2010), multiplicando o preço atual da ação da empresa pelo número de ações da mesma empresa disponíveis no mercado.

\subsubsection{Prêmio de risco do mercado}

Segundo Titman e Martin (2010), o prêmio de risco do mercado é determinado calculando a diferença entre o retorno de uma carteira de mercado e o retorno de um título livre de risco. Como visto anteriormente, é possível estimar a taxa livre de risco observando os retornos dos títulos do tesouro dos Estados Unidos nos últimos 10 a 20 anos. Seguindo a mesma metodologia, Copeland et al. (2002) afirmam que o retorno do mercado pode ser calculado a partir da média geométrica dos retornos anuais dos últimos 10 a 20 anos do índice S\&P 500 . 


\subsection{Risco país}

O risco país, pode ser entendido como uma medida de classificação do risco geral de um país em função da sua economia. Como forma padrão de mercado, o custo do capital próprio é calculado utilizando as taxas de retorno de títulos dos Estados Unidos (DAMODARAN, 1997). Por este motivo, se torna necessário ajustar devidamente essas taxas com um índice que represente o risco do Brasil, já que a empresa avaliada atua no mercado brasileiro.

Uma das formas do mercado estimar o risco país é utilizando o índice EMBI+ (Emerging Markets Bond Index Plus), que é calculado pelo J. P. Morgan, um banco de investimentos dos Estados Unidos. Este índice pode ser encontrado no site www.ipeadata.gov.br.

\subsubsection{Valor presente dos fluxos de caixa}

Como último passo do processo de avaliação por fluxo de caixa descontado, deve-se descontar os fluxos de caixa projetados pelo custo médio ponderado de capital (WACC), para assim chegar ao valor presente líquido da empresa (VPL) (TITMAN; MARTIN, 2010).

A figura a seguir, demonstra visualmente a fórmula utilizada para calcular o VPL do ativo, com base no fluxo de caixa livre do projeto e custo médio ponderado de capital.

Figura 10: valor presente do fluxo de caixa livre do projeto

$$
\sum_{\mathrm{t}=1}^{\mathrm{t}=\infty} \frac{\text { FCLP }_{\mathrm{t}}}{(1+\mathrm{WACC})^{\mathrm{t}}}
$$

Fonte: Adaptado de Damodaran (1997, p. 13)

Por fim, após projetar os fluxos de caixa por um determinado período, devese calcular o valor terminal da empresa utilizando o método de perpetuidade dos fluxos de caixa com taxa de crescimento constante (modelo de Gordon), como sugerido por Titman e Martin (2010), e trazê-lo a valor presente para somar ao VPL dos fluxos de caixa projetados, chegando ao valor econômico da empresa. Tal método utiliza as seguintes fórmulas: 
Figura 11: Fórmula da perpetuidade

$\underset{\text { terminal }}{{ }_{n}}=\frac{\operatorname{FCLP}_{n}(1+\mathrm{g})}{(\mathrm{WACC}-\mathrm{g})}$

Fonte: Adaptado de Titman; Martin (2010, p.313)

$$
\begin{aligned}
& \text { FCLP = Fluxo de caixa livre do projeto } \\
& \mathrm{g}=\text { Taxa de crescimento constante } \\
& \text { WACC = Custo médio ponderado de capital } \\
& \mathrm{n}=\text { Último ano projetado no fluxo de caixa }
\end{aligned}
$$

Figura 12: Valor presente da perpetuidade

$\begin{aligned} & \mathrm{VPL} \text { da } \\ & \text { perpetuidade }\end{aligned}=\frac{\text { Valor terminal }}{(1+\mathrm{WACC})}$

Fonte: Adaptado de Titman; Martin (2010, p.313)

\subsection{Simulação de Monte Carlo}

Prever o futuro é um dos grandes desafios para os analistas do mercado financeiro, isto porque há uma série de incertezas e variáveis sobre a economia local e no mundo, além da dificuldade em prever tendências de consumo, entrada de novos concorrentes no mercado, novas tecnologias, crises políticas e econômicas, entre outras razões.

Por este motivo, autores como Titman e Martin (2010), Copeland et al. (2002), Damodaran (1997), entre outros, afirmam que uma das tarefas mais difíceis do processo de valuation é a projeção dos fluxos de caixa. Em muitos casos de avaliação de projetos ou empresas, administradores acabam tomando decisões de investimento erradas, pois estão sendo guiados por projeções errôneas que não levam em consideração tais incertezas.

Devido a isto, foram desenvolvidas técnicas e modelos matemáticos com o intuito de identificar os possíveis risco de um investimento e considerá-los em uma análise quantitativa. Alguns exemplos de técnicas aplicadas nestes casos são: o diagrama da árvore de decisão e a simulação de Monte Carlo.

De acordo com Titman e Martin (2010), a árvore de decisão é uma ferramenta que ilustra a flexibilidade de um projeto e como as decisões futuras 
podem afetar seu valor. Além disso, pode ser vista também, como um mapa dos possíveis resultados de uma combinação de escolhas. Sendo assim, permite que o administrador compare inúmeras possibilidades de resultados e suas probabilidades de ocorrência e, por consequência, tome a melhor decisão.

Já a simulação de Monte Carlo, pode ser entendida como uma técnica matemática que possibilita a realização de análises quantitativas levando em consideração riscos e tomadas de decisão. É uma ferramenta estatística utilizada para ajudar a identificar as possíveis variações dos principais fatores de influência dos fluxos de caixa futuros de uma empresa ou projeto, através de uma distribuição aleatória de probabilidades (TITMAN; MARTIN, 2010). Por este motivo, Titman e Martin (2010) aconselham a utilização de tal ferramenta para minimizar as incertezas existentes no processo de avaliação.

Para a utilização eficaz da simulação, Titman e Martin (2010) sugerem a realização de três passos. O primeiro passo é preparar as projeções dos fluxos de caixa, assim como descrito anteriormente no tópico 2.2. Em seguida, no segundo passo devem ser definidos os fatores chave para a distribuição de probabilidade e as formas de distribuição a serem utilizadas. Por exemplo, pode ser definida a distribuição triangular para alguns fatores, ou seja, definir um valor mínimo, provável e máximo para que na simulação seja identificada a maior probabilidade de um dos valores acontecer. Outra forma de distribuição é a uniforme, que indica uma mesma probabilidade de diferentes valores acontecerem.

Os fatores chave podem ser diversos, como por exemplo: vendas no primeiro ano; taxa de crescimento das receitas; margem bruta; despesas operacionais / vendas; lucro bruto / vendas; entre outros. Uma ferramenta importante para auxílio na escolha de tais fatores, é o diagrama de tornado. Através da análise deste gráfico, é possível visualizar os impactos das variações de cada fator no valor final da empresa, além disso, pode-se também identificar quais variáveis possuem maior influência na composição deste valor.

O terceiro e último passo, é a execução e interpretação da simulação de Monte Carlo através de um software de análise, como por exemplo, o @Risk. O principal objetivo na análise da simulação não é definir um valor exato para o ativo que está sendo avaliado, mas sim, indicar a probabilidade de ocorrência de diferentes resultados tendo em vista os riscos envolvidos. 


\subsection{Outros modelos da avaliação}

Outro modelo de avaliação bastante difundido no mercado é a avaliação relativa de ativos, que consiste em avaliar uma empresa com base em valores de mercado de ativos similares. Podem ser usados por exemplo múltiplos de EBITDA, preço do metro quadrado de uma casa, ou até os lucros por ação de uma empresa. Segundo Titman e Martin (2010), existem quatro etapas na utilização deste modelo, como pode ser observado a seguir.

1-- Identificar ativos comparáveis e seus respectivos preços de mercado. Esta é a etapa de maior criticidade do processo, visto que, as empresas a serem escolhidas devem ser de fato compatíveis com a empresa avaliada, para haver qualidade no modelo.

2- Calcular uma métrica de avaliação para utilizar no modelo. Ou seja, deve ser definido um múltiplo para calcular o valor da empresa avaliada. Por exemplo, pode ser definido como múltiplo o valor do EBTIDA da empresa similar dividido pelo seu valor de mercado. Depois de calculados, deve ser feito uma média dos múltiplos de todas as empresas comparáveis, e assim chegar a um múltiplo ideal.

$3^{\text {a- }}$ - Faça a primeira estimativa de valor da empresa avaliada. Multiplique 0 índice de avaliação (múltiplo) encontrado das empresas comparáveis pelo valor do EBITDA do último ano da empresa avaliada.

4-. Se necessário, devem-se fazer ajustes na estimativa inicial como base nas características específicas do investimento. Outra opção pode ser ajustar o índice de avaliação das empresas comparáveis. 


\section{Metodologia}

\subsection{Coleta de dados}

Esta seção tem por objetivo estimar o valor de mercado de uma empresa listada na bolsa de valores do Brasil (BM\&FBOVESPA), tendo como ferramentas o modelo de avaliação por fluxo de caixa descontado e a simulação de Monte Carlo. Para a realização deste estudo, foi utilizada a coleta de dados de fontes secundárias, tais como: As demonstrações contábeis e financeiras auditadas da empresa TIM PARTICIPACOES S.A. e seu plano estratégico para os anos de 2018 a 2020, disponíveis no site da empresa; O Beta do setor disponível no site www.damodaran.com; O risco país disponível no site www.ipeadata.gov.br; o valor cotado da ação da Tim, encontrado no site www.bmfbovespa.com.br e a receita bruta do setor de telecomunicações no site www.consult.teleco.com.br.

\subsection{Projeção dos fluxos de caixa}

Os fluxos de caixa foram projetados por um período de 5 anos, assim como sugerem Copeland et al. (2002). As taxas de crescimento, tanto de receita quanto de custos e despesas, foram obtidas principalmente pela análise dos resultados dos anos anteriores, utilizando o cálculo da taxa média geométrica sugerida por Damodaran (1997).

Para realizar a estimativa depreciação/amortização, Capex e capital de giro para os anos projetados, foi utilizado a média móvel de 10 anos dos resultados da empresa. Tais informações podem ser encontradas nas demonstrações financeiras divulgadas pela companhia.

\subsection{Cálculo do WACC}

Para estimar o WACC, calculou-se o custo capital de terceiros, através da análise das demonstrações financeiras da empresa, assim como a proporção de capital de terceiros investida nela. Além disso, foi utilizado o modelo CAPM para estimar o seu custo de capital próprio, observando a técnica de alavancagem do beta proposta por Damodaran (1997). 
Para o cálculo da taxa livre de risco, utilizada no modelo do CAPM, foi considerado a taxa de retorno média dos títulos do tesouro dos Estados Unidos com vencimento de 10 anos. Através de dados disponíveis no site www.damodaran.com, foi possível calcular a taxa livre de risco utilizando a média geométrica dos retornos anuais do índice T-bond 10 nos últimos 20 anos.

O retorno do mercado pode ser calculado a partir da média geométrica dos retornos anuais dos últimos 20 anos do índice S\&P 500.

\subsection{Desconto dos fluxos de caixa}

O valor presente do fluxo de caixa foi calculado descontando os fluxos de caixa projetados para os 5 anos pelo WACC. Em seguida, utilizou-se o método de perpetuidade com taxa de crescimento constante para realizar o cálculo do valor residual da empresa, a partir do fluxo de caixa livre do projeto do último ano projetado. Foi utilizada uma taxa de $1,7 \%$ para o cálculo da perpetuidade.

\subsection{Aplicação da simulação de Monte Carlo}

A partir da projeção dos fluxos de caixa e analise dos resultados, foram definidos como variáveis chave a taxa de crescimento da receita bruta, o WACC e a taxa de perpetuidade (g). A simulação de Monte Carlo foi realizada com 100.000 interações entre estas variáveis. 


\section{Apresentação e análise dos resultados}

\subsection{Sobre a Tim}

A Tim Participações S.A. atua no setor de telecomunicações e está presente em todo território brasileiro. Suas atividades operacionais são realizadas através de suas subsidiárias, Tim Celular S.A. e Intelig Telecomunicações LTDA. Suas operações iniciaram no Brasil em 1998, sendo desde o início, pioneira na inovação de serviços e tecnologias de telecomunicação.

Hoje a Tim está entre as maiores empresas do setor, com presença em cerca de 2.958 cidades do Brasil. Sua base de clientes, conforme demonstrado na apresentação de resultados do segundo trimestre de 2018 divulgado pela própria empresa, considerando a telefonia móvel, fixa e usuários de serviços de internet de banda larga, totaliza aproximadamente 57.722 mil clientes, representando um Market Share de $24,3 \%$ do mercado.

No decorrer de sua história, foi pioneira no lançamento de diversos serviços e produtos, como por exemplo, a introdução de mensagens de texto com imagens e arquivos de mídia (MMS) e o lançamento do famoso BlackBerry no Brasil. Além disso, a companhia ganhou destaque também sendo a operadora que faz planos e promoções que revolucionam. A Tim lançou o plano baseados no conceito de incentivo ao uso (tarifa por chamada e uso ilimitado de dados).

A empresa está listada na bolsa de valores de São Paulo (BM\&F Bovespa), no segmento de listagem Novo Mercado, destinado à negociação de ações emitidas por empresas que se comprometem, voluntariamente, com a adoção de práticas de governança corporativa adicionais em relação ao que é exigido pela legislação. Dentre estes compromissos, pode-se destacar a apresentação de informações visando facilitar o acompanhamento dos resultados financeiros, operacionais e da administração da companhia. Além disso, a mesma adere regras societárias para melhor equilibrar os direitos dos acionistas, sendo eles majoritários ou minoritários. 


\subsubsection{Composição acionária}

A Tim Participações é controlada pela Tim Brasil Serviços e Participações S.A., subsidiária do grupo Telecom Itália. O grupo Telecom Itália possui 100\% do controle da Tim Brasil. A composição acionária está dividida em $67 \%$ de participação da Tim Brasil Serviços e Participação S. A. e 33\% de acionistas minoritários, com um total de 2.419.889.700 ações. Conforme demonstrado no quadro a seguir.

Figura 13: Composição acionária da Tim

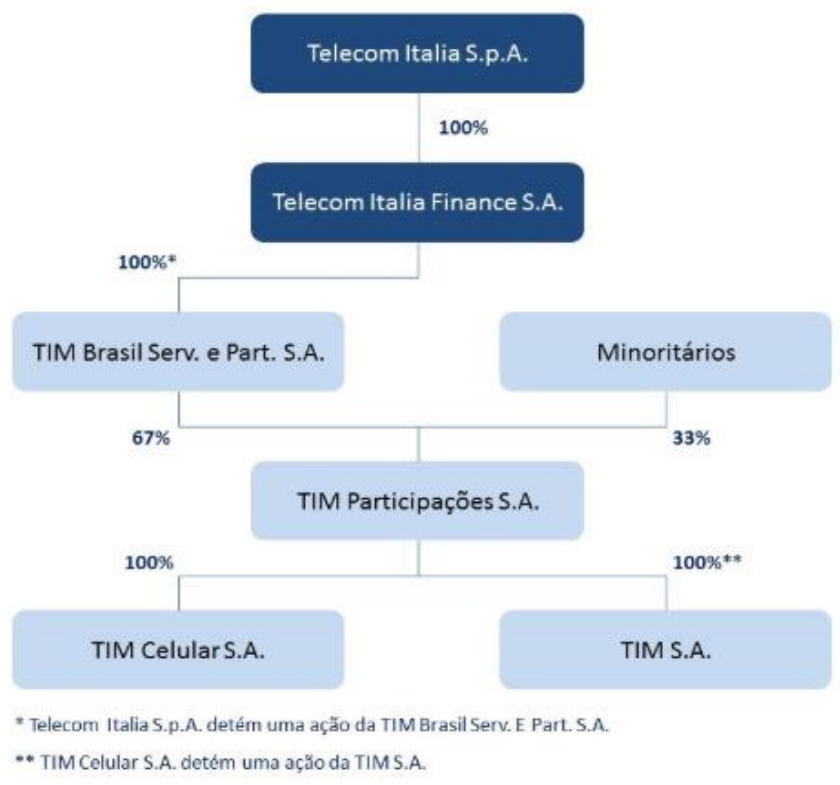

Fonte: ri.tim.com.br

\subsection{Avaliação da companhia}

O processo de valuation será realizado em três passos, conforme descrito na figura 4 do referencial teórico. Sendo esses, a projeção dos fluxos de caixa, a estimativa da taxa de desconto e o desconto dos fluxos de caixa projetados.

\subsubsection{Principais premissas}

\subsubsection{Premissas para a projeção dos fluxos de caixa}

Para estimar os valores futuros dos fluxos de caixa da Tim, foi utilizada a análise histórica de resultados, com base nas demonstrações financeiras da companhia, encontradas em seu próprio site. Para isso, foram utilizados os resultados dos últimos 10 anos, como demonstrado a seguir. 
Figura 14: DRE consolidada da Tim Participações

\begin{tabular}{|c|c|c|c|c|c|c|c|c|c|c|}
\hline DRE *RS Mil & 2008 & 2009 & 2010 & 2011 & 2012 & 2013 & 2014 & 2015 & 2016 & 2017 \\
\hline Receita Bruta & 18.320 .931 & 18.156 .662 & 20.319 .295 & 24.757 .565 & 27.755 .813 & 29.661 .753 & 29.008 .947 & 25.771 .500 & 22.745 .590 & 22.611 .075 \\
\hline Impostos e Descontos & $(5.173 .756)$ & $(5.050 .727)$ & $(5.861 .846)$ & $(7.671 .589)$ & $(8.991 .865)$ & (9.696.553) & $(9.506 .830)$ & $(8.629 .235)$ & $(7.128 .176)$ & $(6.377 .116)$ \\
\hline Receita Liquida & 13.147.175 & 13.105.935 & 14.457.449 & 17.085 .976 & 18.763.947 & 19.965 .200 & 19.502.116 & 17.142.265 & 15.617.413 & 16.233 .959 \\
\hline Opex & $(9.357 .673)$ & (9.239.211) & (10.244.399) & (12.427.669) & (13.753.914) & $(14.727 .802)$ & (13.966.997) & (11.739.834) & $(10.408 .046)$ & (10.286.935) \\
\hline EBITDA & 3.789 .502 & 3.866 .724 & 4.213.051 & 4.658.307 & 5.010 .033 & 5.237 .399 & 5.535.120 & 6.613.411 & 5.209 .367 & 5.947 .023 \\
\hline Margem EBITDA & $28,8 \%$ & $29,5 \%$ & $29,1 \%$ & $27,3 \%$ & $26,7 \%$ & $26,2 \%$ & $28,4 \%$ & $38,6 \%$ & $33,4 \%$ & $36,6 \%$ \\
\hline Depreciação e Amortização & (3.298.629) & $(3.389 .699)$ & $(3.012 .916)$ & (2.595.968) & (2.688.588) & $(2.798 .526)$ & $(3.052 .579)$ & (3.361.971) & (3.785.172) & $(4.013 .671)$ \\
\hline EBIT & 490.873 & 477.025 & 1.200 .134 & 2.062.339 & 2.321 .445 & 2.438 .873 & 2.482 .541 & 3.251 .440 & 1.424.196 & 1.933 .352 \\
\hline Resultado Financeiro Liquido & $(374.975)$ & $(256.616)$ & $(245.457)$ & $(238.857)$ & $(167.965)$ & $(302.720)$ & $(280.642)$ & (250.406) & $(410.880)$ & (497.836) \\
\hline Lucro Antes dos Impostos & 115.898 & 220.409 & 954.677 & 1.823.481 & 2.153 .480 & 2.136 .153 & 2.201 .899 & 3.001 .034 & 1.013 .316 & 1.435 .516 \\
\hline Imposto de Renda e Contribuição Social & 64.254 & (5.516) & 1.257 .038 & $(545.636)$ & (704.592) & $(610.308)$ & (652.796) & (915.591) & $(262.889)$ & $(201.009)$ \\
\hline Lucro Liquido & 180.152 & 214.893 & 2.211.715 & 1.277 .845 & 1.448 .888 & 1.525 .845 & 1.549 .102 & 2.085 .443 & 750.427 & 1.234 .507 \\
\hline Margem Liquida & $1,4 \%$ & $1,6 \%$ & $15,3 \%$ & $7,5 \%$ & $7,7 \%$ & $7,6 \%$ & $7,9 \%$ & $12,2 \%$ & $4,8 \%$ & $7,6 \%$ \\
\hline
\end{tabular}

Fonte: Elaboração própria com base nas demonstrações financeiras da TIM

\subsection{Receita bruta e Opex}

Para a projeção da Receita Bruta e Opex, considerou-se a variação média dos últimos 10 anos de operação, sendo essas, 2,9\% e 1,7\% respectivamente. 0 gráfico a seguir demonstra a variação anual dos valores.

Figura 15: Variação da Receita Bruta e Opex

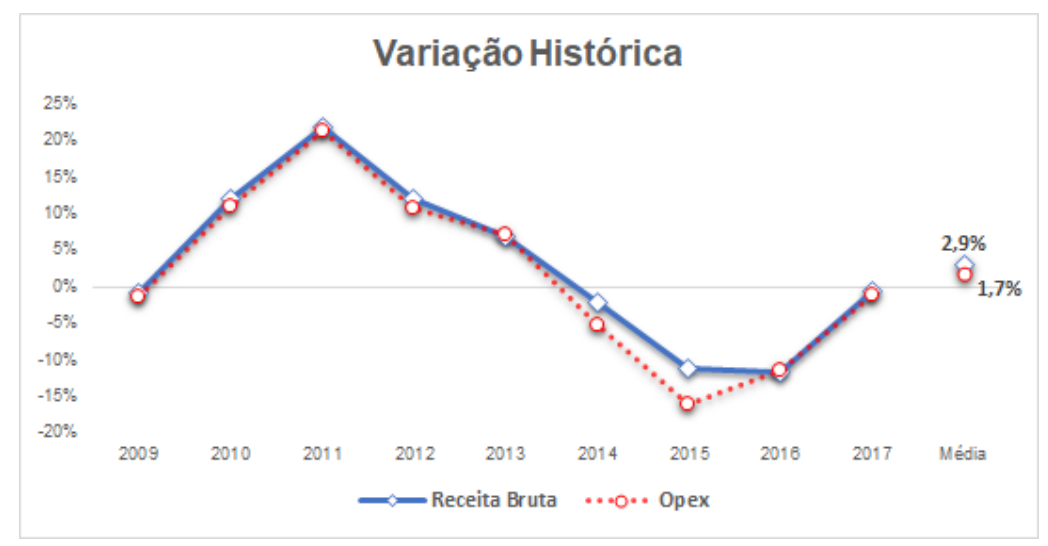

Fonte: Elaboração própria

\subsection{Impostos e descontos sobre a receita e IR}

Para estimativa do valor de impostos e descontos sobre a Receita Bruta, foi utilizada a média das taxas dos últimos 10 anos. Como resultado, foi encontrada a taxa média de 30,7\%.

Da mesma maneira, foram calculadas as taxas de IR sobre o lucro antes dos impostos dos últimos 10 anos e utilizado a média destas taxas para a projeção dos resultados. Contudo, após analisar os valores notou-se um resultado incomum das taxas de IR nos anos de 2008 a 2010, em virtude de incentivos fiscais e do reconhecimento de créditos tributários relativos à sua subsidiária TIM Nordeste S.A. Por este motivo, foram desconsiderados do cálculo os anos de 2008, 2009 e 
2010 e passou-se a utilizar a taxa média dos últimos 7 anos. Como resultado, foi encontrada a taxa de IR de $27,3 \%$.

\subsection{Depreciação e Amortização, Capex e Capital de Giro}

O cálculo da Depreciação/Amortização, Capex e Capital de Giro foi realizado observando a média móvel de 10 anos dos resultados da TIM. Esta premissa foi utilizada com o propósito de não projetar valores muito distintos dos resultados já apresentados pela companhia. O valor total de Capex projetado de 2018 a 2022 foi de $R \$ 18.820$ milhões e os valores de Depreciação/Amortização totalizaram $R \$$ 15.990 milhões. Como demonstrado na figura a seguir.

Figura 16: Média móvel da Depreciação/Amortização, Capex e Capital de Giro

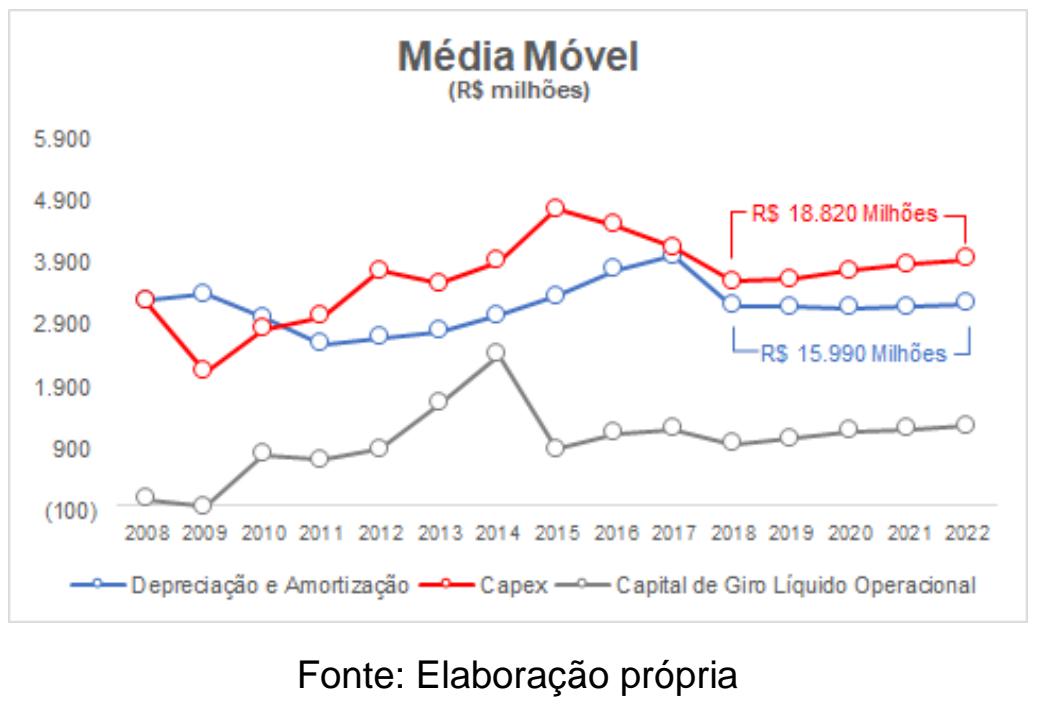

De acordo com a apresentação do plano estratégico divulgado pela Tim, a expectativa é de realização de 12 bilhões de reais em Capex de 2018 a 2020, ou seja, uma média de 4 bilhões por ano. Dessa forma, mantiveram-se em linha os valores projetados neste estudo e o plano estratégico atual da companhia.

O capital de giro foi calculado através da diferença entre o ativo circulante, desconsiderando o caixa, e o passivo circulante, desconsiderando a dívida onerosa. Os valores apresentados no gráfico representam o total de capital de giro que a empresa necessitou por ano. Para a projeção dos fluxos de caixa livre do projeto, foi utilizada a variação do capital de giro de um ano para o outro. 


\subsubsection{Premissas para o cálculo do WACC}

Para o cálculo do WACC, foi considerado a estrutura de capital da TIM no dia 31/12/2017. Dessa forma, observou-se o percentual de participação do capital próprio e do capital de terceiros.

Figura 17: Estrutura de capital da TIM no dia 31/12/2017

\begin{tabular}{|l|c|c|}
\multicolumn{3}{c}{ Estrutura de Capital - R\$ Mil } \\
\hline Dívida + CP & 33.065 .445 & $100 \%$ \\
\hline Capital Próprio & 28.374 .501 & $86 \%$ \\
\hline Dívida & 4.690 .944 & $14 \%$ \\
\hline
\end{tabular}

Fonte: Elaboração própria com base nas demonstrações financeiras da TIM

\subsection{Custo do capital de terceiros}

De acordo com os resultados apresentados nas demonstrações financeiras do $2^{\circ}$ trimestre de 2018, a dívida da Tim está concentrada em contratos de longo prazo, sendo financiada, principalmente, pelo BNDES e com um custo médio de $8,4 \%$ a.a.

Como foi visto no capítulo 2, existe um benefício fiscal associado aos empréstimos obtidos pela companhia, visto que, os juros pagos em virtude da dívida adquirida são dedutíveis do imposto de renda (IR). A taxa de IR calculada para a projeção dos resultados foi de $27,3 \%$. Sendo assim, o custo do capital de terceiros ajustado com o benefício do IR ficou em 6,1\% a.a. Como demonstrado no cálculo a seguir.

Figura 18: Cálculo do custo do capital de terceiros

$$
\mathrm{k}_{d}=8,4 \% *(1-27,3 \%)=6,1 \%
$$

Fonte: Elaboração própria

\subsection{Custo do capital próprio (CAPM)}

As premissas a seguir demonstram o racional utilizado para calcular o custo de capital próprio da TIM. O CAPM foi calculado utilizando a fórmula demonstrada no capítulo 2 e apresentou um custo de capital próprio de 9,96\%. 


\subsection{Beta}

Para o cálculo do beta, foram utilizadas informações do site www.damodaran.com e das demonstrações financeiras da TIM. Deste site, foram extraídos os betas desalavancados dos setores de telecomunicações sem fio, equipamentos de telecomunicações e serviços de telecomunicações e calculouse um beta médio do setor. Por fim, o beta médio foi alavancado de acordo com a estrutura de capital da companhia, conforme a fórmula apresentada no capítulo 2 , e chegou-se a um beta de 0,77 .

Figura 19: Beta desalavancado do setor de telecomunicações

\begin{tabular}{lc} 
Setor & Beta Desalavancado \\
\hline Telecom (Wireless) & 0,59 \\
Telecom. Equipmentos & 0,86 \\
Telecom. Serviços & 0,60 \\
Beta médio & $\mathbf{0 , 6 8}$
\end{tabular}

Fonte: Elaboração própria com base no site www.damodaran.com

Figura 20: Cálculo do Beta alavancado

$$
\beta_{a}=0,68 *\left(1+\left[(1-27,3 \%) *\left(\frac{4.690 .943 .921}{28.374 .500 .654}\right)\right]=0,77\right.
$$

Fonte: Elaboração própria

\subsection{Prêmio de risco}

Segundo Titman e Martin (2010), o prêmio de risco do mercado é determinado calculando a diferença entre o retorno de uma carteira de mercado $e$ o retorno de um título livre de risco. Para este estudo, o retorno do mercado e a taxa livre de risco foram calculados através da média geométrica dos retornos anuais dos últimos 20 anos dos índices S\&P 500 e T-Bond 10 anos.

Foi utilizado o período de 20 anos para o cálculo da média geométrica, pois, o mesmo contempla períodos de crise e recuperação do mercado americano e brasileiro e, portanto, não foi necessário realizar ajustes ou desconsiderar os anos de baixo e alto retorno.

Figura 21: Cálculo do prêmio de risco do mercado

\begin{tabular}{|c|c|c|c|}
\hline Período & S\&P 500 & T - Bond 10 anos & Prêmio de risco \\
\hline $\mathbf{1 9 2 8}$ - 2017 & $9,65 \%$ & $4,88 \%$ & $4,77 \%$ \\
\hline $\mathbf{1 9 9 8 - 2 0 1 7}$ & $7,12 \%$ & $4,99 \%$ & $2,14 \%$ \\
\hline
\end{tabular}

Fonte: Elaboração própria com base no site www.damodaran.com 
Sendo assim, os resultados obtidos foram uma taxa livre de risco de 4,99\% a.a., um retorno do mercado de $7,12 \%$ a.a. e por consequência, um prêmio de risco de $2,14 \%$ a.a.

\subsection{Risco país}

Como visto anteriormente, uma das formas utilizadas pelo mercado para medir o risco país é a utilização do índice EMBI+ (Emerging Markets Bond Index Plus), calculado pelo banco J. P. Morgan e pode ser encontrado no site www.ipeadata.gov.br.

O EMBI+ é calculado com base nos bônus (títulos de dívida) emitidos pelos países emergentes e, por este motivo, optou-se por utilizar o índice mais recente possível, a fim de capturar o momento atual vivido pelos países emergentes. Portanto, foi utilizado o EMBI+ do dia 16/09/2018, que de acordo com o site www.ipeadata.gov.br foi de 3,34\%.

\subsection{Cálculo do custo do capital próprio}

Figura 22: Cálculo do custo do capital próprio

$$
k_{e}=4,99 \%+0,77^{*}(7,12 \%-4,99 \%)+3,34 \%=9,96 \%
$$

Fonte: Elaboração própria

\subsubsection{Premissas para o cálculo da taxa de crescimento (g)}

Para estimar uma taxa de crescimento para o negócio, foi utilizada a variação média dos últimos 5 anos da receita bruta do setor de telecomunicações no Brasil. Tal informação, foi obtida no site consult.teleco.com.br. Este site é responsável por uma série de pesquisas e dados do setor de telecomunicações no Brasil e, portanto, divulgam informações de alta qualidade e confiança.

O gráfico a seguir demonstra a receita bruta do setor de telecomunicações no Brasil e seus respectivos índices de crescimento. 
Figura 23: Receita bruta do setor de telecomunicações no Brasil

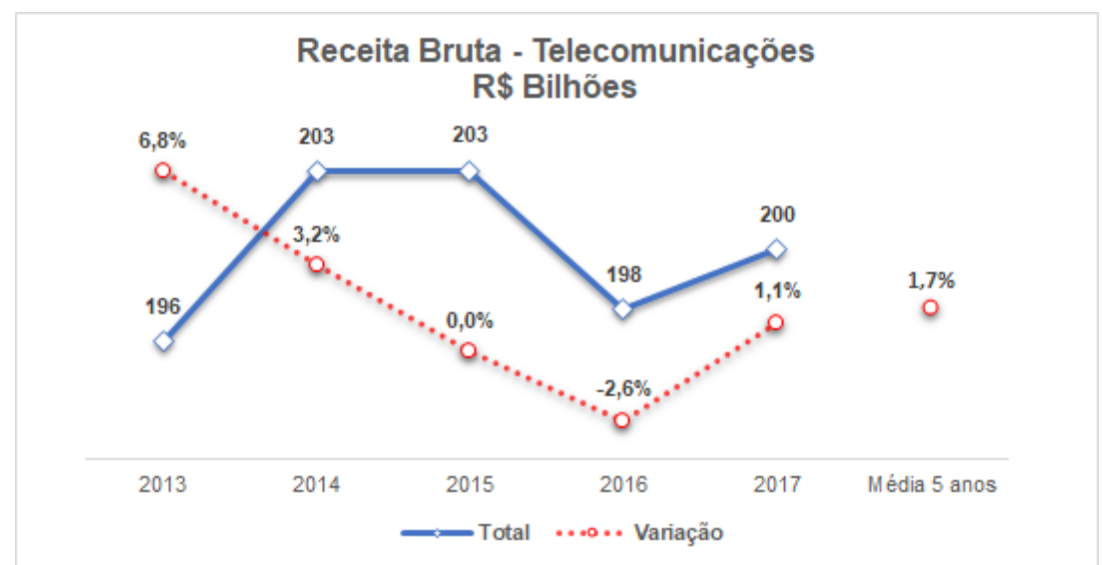

Fonte: Elaboração própria com base no site www.consult.teleco.com.br

Como resultado, foi estimado uma taxa de crescimento (g) para o negócio de $1,7 \%$ ao ano.

\subsubsection{Projeção do fluxo de caixa livre do projeto}

Tendo como base todas as premissas demonstradas anteriormente, foram realizadas as projeções dos fluxos de caixa para os próximos 5 anos de operação da TIM, como indica o primeiro passo do processo de avaliação demonstrado no capítulo 2.

Figura 24: Projeção do fluxo de caixa livre do projeto (FCLP)

\begin{tabular}{|c|c|c|c|c|c|}
\hline DRE *R\$ Mil & 2018 & 2019 & 2020 & 2021 & 2022 \\
\hline Receita Bruta & 23.267 .814 & 23.943 .629 & 24.639 .072 & 25.354 .715 & 26.091 .143 \\
\hline Impostos e Descontos & $(7.138 .037)$ & $(7.345 .361)$ & (7.558.707) & $(7.778 .250)$ & $(8.004 .170)$ \\
\hline Receita Líquida & 16.129 .778 & 16.598 .268 & 17.080 .365 & 17.576 .465 & 18.086 .974 \\
\hline Opex & $(10.459 .053)$ & $(10.634 .051)$ & $(10.811 .977)$ & $(10.992 .880)$ & $(11.176 .810)$ \\
\hline EBITDA & 5.670 .724 & 5.964 .216 & 6.268 .388 & 6.583 .585 & 6.910 .164 \\
\hline Margem EBITDA & $35,2 \%$ & $35,9 \%$ & $36,7 \%$ & $37,5 \%$ & $38,2 \%$ \\
\hline Depreciação e Amortização & $(3.199 .772)$ & $(3.189 .886)$ & (3.169.905) & $(3.185 .604)$ & (3.244.567) \\
\hline EBIT & 2.470 .952 & 2.774 .330 & 3.098 .483 & 3.397 .981 & 3.665 .597 \\
\hline Imposto de Renda e Contribuição Social & $(675.326)$ & $(758.240)$ & $(846.833)$ & (928.688) & $(1.001 .829)$ \\
\hline NOPAT & 1.795 .627 & 2.016 .090 & 2.251 .649 & 2.469 .293 & 2.663 .768 \\
\hline Depreciação e Amortização & 3.199 .772 & 3.189 .886 & 3.169 .905 & 3.185 .604 & 3.244 .567 \\
\hline Capex & $(3.595 .074)$ & $(3.627 .368)$ & (3.775.255) & $(3.869 .205)$ & (3.953.414) \\
\hline Variação do Capital de Giro & 247.919 & $(88.436)$ & $(110.039)$ & $(37.736)$ & $(50.131)$ \\
\hline Fluxo de Caixa Livre do Projeto (FCLP) & 1.648 .243 & 1.490 .172 & 1.536 .260 & 1.747 .956 & 1.904 .790 \\
\hline
\end{tabular}

Fonte: Elaboração própria

\subsubsection{Cálculo do WACC}

Seguindo o segundo passo do processo de avaliação de empresas, é necessário estimar uma taxa de desconto adequada ao risco do negócio, para que seja possível trazer os fluxos de caixa projetados a valor presente. Com as 
premissas adotadas, o cálculo do WACC resultou em uma taxa de desconto de $9,18 \%$. Os cálculos foram realizados com base na fórmula a seguir.

Figura 25: Cálculo do WACC

$$
\text { WACC }=6,1 \% * 14 \%+9,96 \% * 86 \%=9,18 \%
$$

Fonte: Elaboração própria

\subsubsection{Resultado da avaliação}

Por fim, o último passo do processo de avaliação de uma empresa é descontar seus fluxos de caixa projetados pelo WACC, a fim de trazê-los a valor presente. Junto a isto, deve-se calcular o valor da perpetuidade dos fluxos de caixa, conforme demonstrado na figura 12 do capítulo 2. Dessa forma, calculouse o valor presente (VPL) dos fluxos de caixa projetados de 2018 a 2022 , chegando ao valor de $\mathrm{R} \$ 6.986$ milhões e um valor terminal de $\mathrm{R} \$ 25.959$ milhões. O quadro a seguir demonstra, de forma resumida, todos os valores calculados durante o processo de avaliação da companhia e o valor implícito por ação após incluir o valor do caixa e excluir o endividamento oneroso de 2017.

Figura 26: Principais resultados da avaliação

\begin{tabular}{lr}
\hline \multicolumn{2}{c}{ Resumo da avaliação - R\$ mil } \\
WACC & $9,18 \%$ \\
Taxa de crecimento (g) & $1,7 \%$ \\
Valor Presente Líquido (VPL) & 6.985 .559 \\
Valor terminal 2022 & 25.958 .703 \\
VPL do valor terminal & 16.733 .121 \\
(+) Caixa em 31/12/2017 & 2.960 .718 \\
\hline Valor implícito do empreendimento & 26.679 .399 \\
\hline$(-)$ Endividamento oneroso em 31/12/2017 & $(4.690 .944)$ \\
\hline Valor implícito do capital próprio & 21.988 .455 \\
\hline Número de ações & 2.421 .032 \\
\hline Valor implícito por ação-alvo & 9.08 \\
\hline
\end{tabular}

Fonte: Elaboração própria

O valor por ação encontrado através do modelo utilizado neste estudo, pode ser comparado ao preço da ação do dia 17 de setembro de 2018. O gráfico a seguir, retirado do site ri.tim.com.br, demonstra que o preço da ação em $17 / 09 / 2019$ era de $\mathrm{R} \$ 11,70$ (28,8\% maior que o valor calculado com o modelo proposto no estudo). 
Figura 27: Cotação da Tim em 17/09/2018

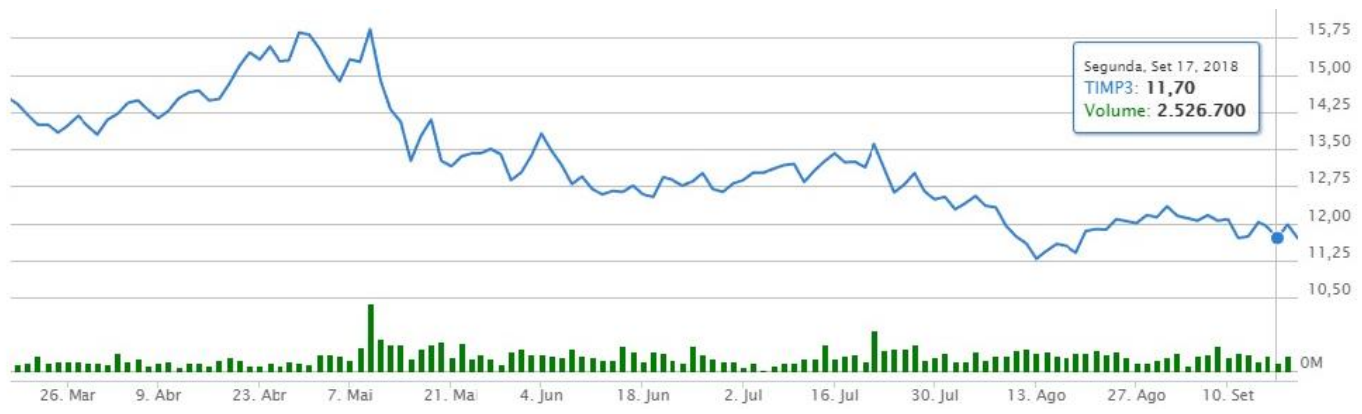

Fonte: Site ri.tim.com.br

\subsection{Simulação de Monte Carlo}

Como tratado no início deste estudo, todo método de avaliação, mesmo o mais sofisticado, envolve um grande nível de incerteza. Isso porque, as premissas utilizadas podem ter algum tipo de viés ou erro, o cenário econômico do país pode se alterar de forma brusca, além de outros motivos.

Por isto, foi proposta a utilização da simulação de Monte Carlo como uma ferramenta de análise das possíveis variações do valor do ativo, a fim de identificar as variáveis que mais o afetam e a probabilidade do mesmo aumentar ou diminuir. Para tal, foi utilizado o software @Risk que fornece as ferramentas necessárias para a realização da simulação.

O gráfico a seguir, conhecido como diagrama de tornado, aponta qual variável tem maior sensibilidade e influência no valor da companhia, mostrando com isso, que uma pequena alteração nessa premissa pode levar a uma grande mudança no preço da ação. Analisando o gráfico, pode-se notar que a premissa de crescimento da receita bruta tem a maior influência no preço da ação e, por este motivo, a mesma pode ser entendida como uma variável que agrega grande risco ao modelo de avaliação, pois, se for definida uma taxa que não represente adequadamente a tendência da empresa, o valor encontrado no final da avaliação sofrerá grandes desvios. 
Figura 28: Diagrama de tornado

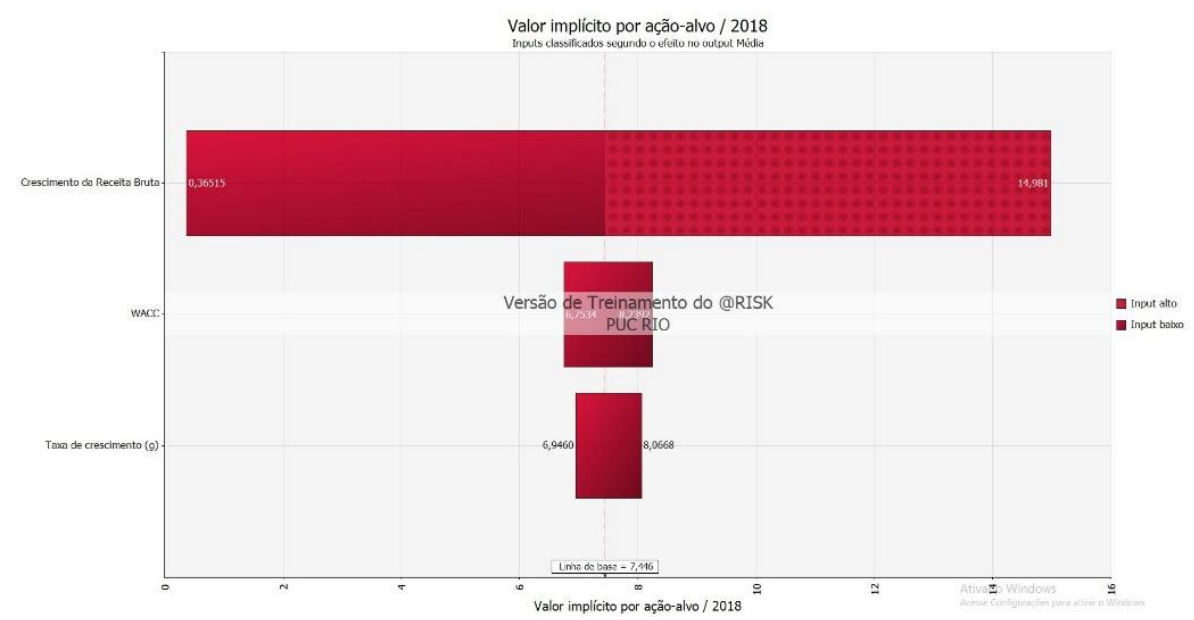

Fonte: Elaboração própria com auxílio do @Risk

Com o uso das simulações apresentadas neste gráfico, foram selecionadas como variáveis chave o crescimento da receita bruta, o WACC e a taxa de crescimento $(\mathrm{g})$ e definidas como distribuição triangular, onde se adotou um valor mínimo, máximo e mais provável para cada uma das variáveis. A modelagem utilizada na simulação de Monte Carlo está demonstrada a seguir.

Figura 29: Modelagem da simulação de Monte Carlo

\begin{tabular}{|l|c|c|c|c|}
\hline & Mínimo & médio & Máximo & Distribuição \\
\hline Crescimento da Receita Bruta & $-2,6 \%$ & $2,1 \%$ & $6,8 \%$ & Triangular \\
\hline WACC & $8,2 \%$ & $9,2 \%$ & $10,2 \%$ & Triangular \\
\hline Taxa de crescimento $(\mathrm{g})$ & $0,7 \%$ & $1,7 \%$ & $2,7 \%$ & Triangular \\
\hline
\end{tabular}

Fonte: Elaboração própria com auxílio do @Risk

O próximo gráfico demonstra o intervalo de possíveis resultados e a probabilidade relativa de ocorrência dos mesmos. De acordo com o resultado da simulação de Monte Carlo, há uma probabilidade de $65 \%$ de o preço da ação ficar abaixo de $\mathrm{R} \$ 9,08$ e, por consequência, a probabilidade do preço ficar acima é de $35 \%$. Ou seja, há uma possibilidade relevante de que o preço da ação fique abaixo do valor projetado neste estudo. Além disso, o resultado da simulação apontou um desvio padrão para o preço da ação de $R \$ 4,30$. 
Figura 30: Gráfico de distribuição de frequência

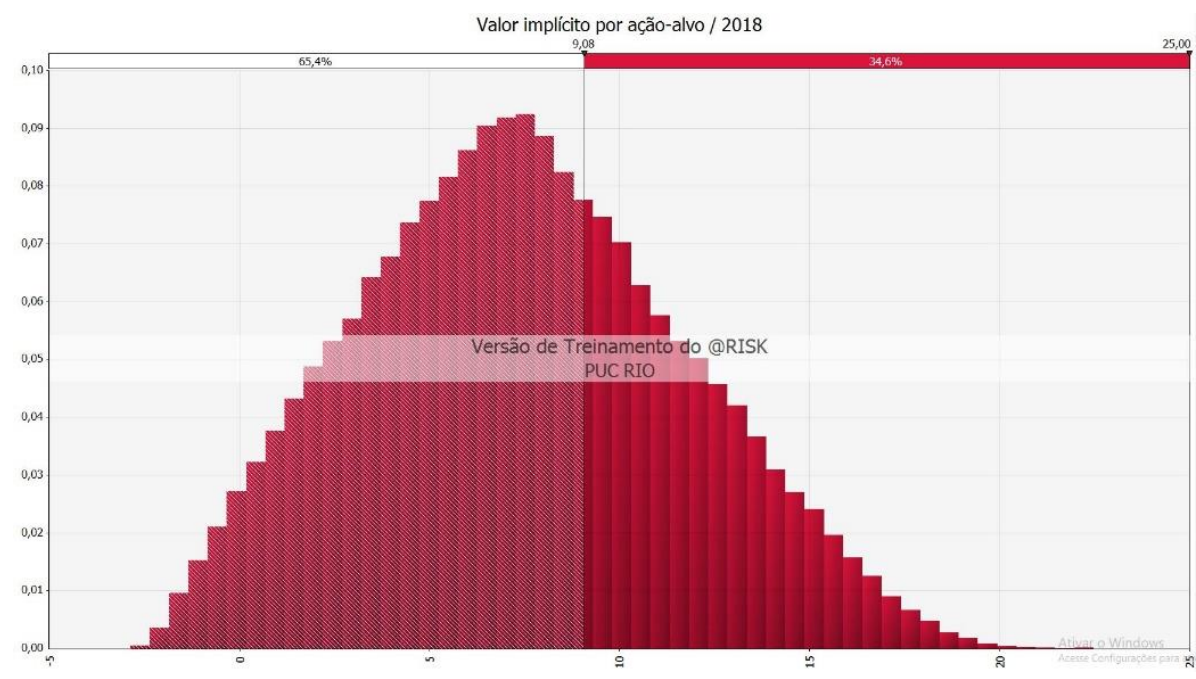

Fonte: Elaboração própria com auxílio do @Risk 


\section{Conclusões}

Como objetivo principal, este estudo propôs a aplicação da metodologia de avaliação de empresas por fluxo de caixa descontado, auxiliada da simulação de Monte Carlo, com o intuito de minimizar os efeitos de viés e das incertezas oriundas das projeções financeiras. Para tal, calculou-se o custo de capital da empresa TIM e foi apresentado de forma detalhada todo o processo de avaliação por fluxo de caixa descontado e realização da simulação de Monte Carlo.

Como resultado inicial, utilizando o tradicional modelo de avaliação por fluxo de caixa descontado, foram obtidos através dos cálculos e premissas apresentados neste trabalho, um valor de mercado para a companhia de $R \$ 22,0$ bilhões e um preço de $\mathrm{R} \$ 9,08$ por ação. O preço da ação da Tim no dia 17 de setembro de 2018 era de $R \$ 11,70$.

Realizada a simulação de Monte Carlo, tendo como principais premissas a taxa de crescimento da receita bruta, o WACC e a taxa de perpetuidade ( $\mathrm{g}$ ), foram executadas 100.000 interações entre as premissas selecionadas. O resultado da simulação mostra uma probabilidade de $65 \%$ de o preço da ação estar abaixo de $\mathrm{R} \$ 9,08$ e $35 \%$ de chance do preço ficar acima.

Entende-se, portanto, que muitas vezes a principal função de uma análise prospectiva não é, necessariamente, acertar o valor exato que se realizará, mas sim, auxiliar as decisões presentes demonstrando os possíveis risco futuros.

Para futuros estudos de avaliação da Tim, sugere-se a realização de entrevistas com gestores da companhia e com analistas de mercado que acompanham a empresa, além da inclusão de novas variáveis na simulação de Monte Carlo e a utilização de outros métodos de avaliação, como por exemplo, o método de múltiplos de mercado. 


\section{Referências Bibliográficas}

BM\&FBOVESPA. EMPRESAS LISTADAS. Disponível em: http://www.bmfbovespa.com.br/pt br/produtos/listados-a-vista-ederivativos/renda-variavel/empresas-listadas.htm. Acesso em: 11 de agosto de 2018.

COPELAND, T.; KOLLER, T.; MURRIN, J. Avaliação de empresas - valuation: calculando e gerenciando o valor das empresas. São Paulo: Pearson Makron Books, 2002. 499 p.

DAMODARAN, Aswath. Avaliação de investimentos. Rio de Janeiro: Qualitymark, 1997.

DAMODARAN, A. A. BETA DOS SETORES. Disponível em: http://pages.stern.nyu.edu/ adamodar/New Home Page/datafile/Betas. Acesso em: 16 de setembro de 2018.

DAMODARAN, A. A. RETORNOS ANUAIS EM AÇÕES, T.BONDS E T.BILLS: 1928 - ATUAL. Disponível em: http://pages.stern.nyu.edu/ adamodar/New Home Page/datafile/histretSP.html. Acesso em: 30 de setembro de 2018.

JP MORGAN. EMBI+ RISCO-BRASIL. Disponível em: http://www.ipeadata.gov.br/ExibeSerie.aspx?serid=40940\&module=M. Acesso em: 16 de setembro de 2018.

LEAL, R. P. C. Revisão da literatura sobre estimativa de custo de capital aplicada ao Brasil. Rio de Janeiro: COPPEAD/UFRJ, 2002.

MARQUES, VAGNER ANTONIO; DINIZ, TIAGO CANÇADO. A influência do fator risco nos modelos de valuation. XXX ENCONTRO NACIONAL DE ENGENHARIA DE PRODUÇÃO, São Carlos. Anais, 2010.

MARTELANC, R.; PASIN, R.; PEREIRA, F. Avaliação de empresas: um guia para fusões \& aquisições e private equity. São Paulo: Pearson Prentice Hall, 2010. $302 \mathrm{p}$.

TELECO. INTELIGÊNCIA EM TELECOMUNICAÇÕES. Disponível em: http://consult.teleco.com.br/basedados.asp. Acesso em: 22 de setembro de 2018.

TIM Participações S.A. DIVULGAÇÃO DE RESULTADOS. Disponível em: http://ri.tim.com.br/ListResultados/Central-de-

Resultados?=8aFYrvuD6r3eo9YseDEvrw==. Acesso em: 22 de setembro de 2018.

TIM Participações S.A. PLANO ESTRATÉGICO 2018 - 2020. Disponível em: http://ri.tim.com.br/ShowApresentacao.aspx?ldApresentacao=AY3sTVmrnWY/og ywmSIVvQ==\&linguagem=pt\#. Acesso em: 22 de setembro de 2018. 
TITMAN, S.; MARTIN, J. D. Avaliação de projetos e investimentos: valuation. [S.I.]: Porto Alegre : Bookman, 2010. 